\title{
Magnetic MFC aerogel for heavy metal ions separation
}

\author{
Jinhua Yan* \\ Guangdong Industry Technical College, Guangzhou 510640 China \\ E-mail: jhyan2013@163.com
}

Keywords: MFC aerogel; Fe3O4; metal ions separation.

\begin{abstract}
Magnetic micro-fibrillated cellulose(MFC) aerogel used as heavy metal ions absorbent was researched in the paper. It was expressed great separation capacity. The absorbent had little effect on contact time in 20-120min range. But it was dependent on ion initial concentration. 4 kinds of ions removal rate were ranked $\mathrm{Cd} 2+>\mathrm{Zn} 2+>\mathrm{Pb} 2+\sim \mathrm{Cr} 6+$ at same ions initial concentration of $100 \mathrm{mg} / \mathrm{l}$; and removal rate ranked $\mathrm{Zn} 2+>\mathrm{Cd} 2+\sim \mathrm{Cr} 6+>\mathrm{Pb} 2+$ at $60 \mathrm{~min}$ contact time and higher initial separation concentrations. Magnetic MFC aerogel is a good absorbent of heavy metal ions in aqueous solution.
\end{abstract}

\section{Introduction}

The removal of heavy metal ions from natural waters and industrial wastewaters is a critical technology due to the environmental strict standard and the more attention to people health. For example, the Word Health Organization (WHO) has announced a maximum $\mathrm{Hg}(\mathrm{II})$ uptake of $0.3 \mathrm{mg} / \mathrm{w}$ and a maximum acceptable $\mathrm{Hg}(\mathrm{II})$ concentration of $1 \mu \mathrm{g} / \mathrm{L}$ in drinking water and the maximum copper limit of $1.0 \mathrm{mg} / \mathrm{L} \mathrm{[1-5].} \mathrm{The} \mathrm{heavy} \mathrm{metal} \mathrm{ions} \mathrm{removal} \mathrm{research}$ has widely been investigated such as chemical precipitation, solvent extraction, ultra filtration, ion exchange and adsorption[6-8]. Adsorption method appears to be the most effective, especially for effluents with moderate and low concentration. Though different types of polymer or mineral adsorbents were developed [9-13], and biopolymer adsorbents gained more attention due to avoiding the secondary pollution. [14,15].

In the current work, we prepared a novel absorbent with magnetic nanoparticles loaded MFC aerogel. SEM and TEM were scanned to observe the particle morphology. The hybrid aerogel application in heavy metal ions separation like $\mathrm{Cr}(\mathrm{VI}), \mathrm{Pb}(\mathrm{II}), \mathrm{Cd}(\mathrm{II})$ and $\mathrm{Hg}(\mathrm{II})$ was conducted in detail.

\section{Experiments}

Magnetic MFC aerogel preparation was described in our previous work elsewhere. The aerogel morphology was scanned in SEM and TEM, and was conducted TGA shown in Figure 1 and Figure 2.

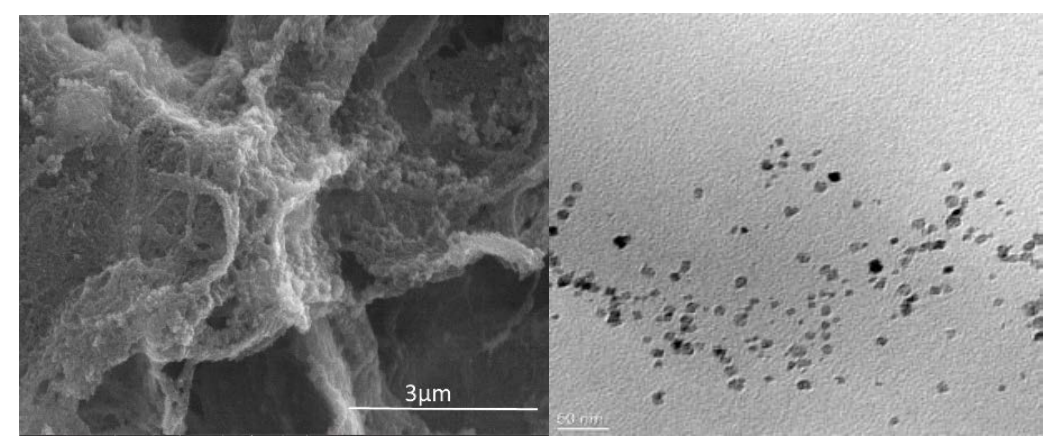

Fig 1 Magnetic MFC aerogel SEM(left) and TEM(right) images 


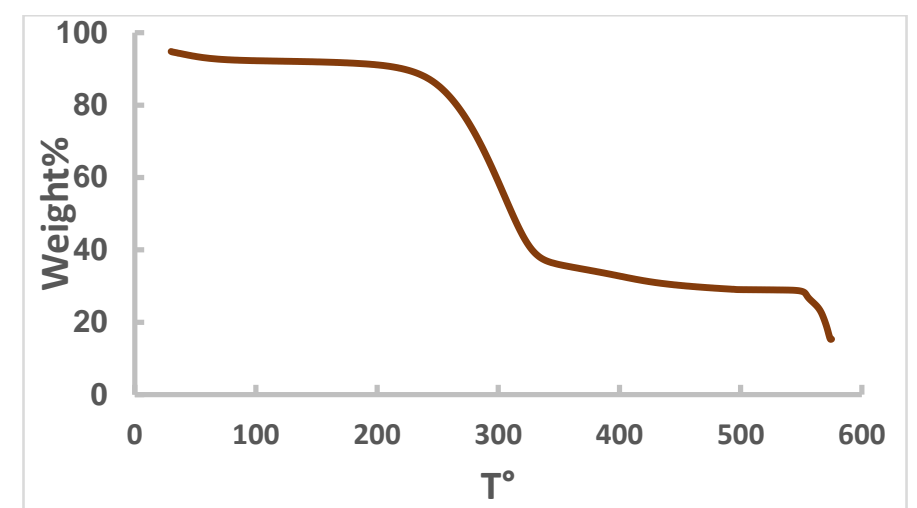

Fig 2 Magnetic MFC aerogel TGA for thermal stability

TGA was conducted in nitrogen air before $500^{\circ} \mathrm{C}$, then in oxygen air between $500-575^{\circ} \mathrm{C}$. The aerogel residual was $15.3 \%$ and $\mathrm{Tg}$ was around $263^{\circ} \mathrm{C}$ which shows the aerogel good stability. This is close to the $18.3 \%$ magnetic ferrite content loaded in hydrogel [16]. The difference is the magnetic aerogel was prepared in $0.05 \mathrm{M} \mathrm{Fe}(\mathrm{II})$ and $0.1 \mathrm{M} \mathrm{Fe}(\mathrm{III})$ mixture for $1 \mathrm{~h}$ before soaking into $0.2 \mathrm{~N} \mathrm{NaOH}$ solution for $1 \mathrm{~h}$ at $60^{\circ} \mathrm{C}$ and Freezer drying, the magnetic hydrogel was prepared in $0.25 \mathrm{M} \mathrm{Fe}(\mathrm{II})$ and $0.5 \mathrm{M} \mathrm{Fe}(\mathrm{III})$ mixture for $12 \mathrm{~h}$ before soaking into $0.5 \mathrm{M} 250 \mathrm{~mL}$ sodium hydroxide solution, and dried in vacuum oven at $40{ }^{\circ} \mathrm{C}$. $5 \mathrm{mg}$ aerogel was taken to absorb heavy metal ions in its $25 \mathrm{~mL}$ aqueous solution. 4 kinds of metal ions, Cr6+, $\mathrm{Zn} 2+, \mathrm{Cd} 2+$ and $\mathrm{Pb} 2+$, were applied. The separation test was conducted as: $5 \mathrm{mg}$ of dry aerogel in $25 \mathrm{~mL}$ of metal solution for some time at stable $\mathrm{pH}$ value of 6 adjusted with $\mathrm{HNO}(0.01 \mathrm{M})$ or $\mathrm{NaOH}(0.01 \mathrm{M})$ using a pH meter. The mixture was centrifuged and filtered. $10 \mathrm{~mL}$ filtrate was taken to measure the residual ions concentration. The Perkin Elmer 8000 ICP-OES was used to analyze the concentration of heavy metal ions. Different contact time and different initial concentration were conducted respectively. All measurements were repeated three times.

\section{Results and discussion}

4 kinds of metal ions solution were separated by the magnetic MFC aerogel using 20-120min different contact time range. The initial metal ions concentration are $100 \mathrm{mg} / \mathrm{L}$. After $5 \mathrm{mg}$ aerogel absorbent was applied, the residual metal ions concentration was measured and recorded in Figure 3. We can see that the contact time has little effect on all metal ions separation since the curves are near flat during 20-120min contact time test range. In other words, the aerogel absorbed the ions very quickly to its absorption equilibrium. Among these 4 ions, Cd2+ removal rate is close to $100 \%$, the residual ion concentration less than $5 \mathrm{mg} / \mathrm{L}$; Zn2+ was removed the second most to $20 \mathrm{mg} / \mathrm{L}$; Cr6+ and Pd2+ were removed the least to near 50\%. The magnetic MFC aerogel performed as very good absorbent for heavy metal ions both good effectivity (short contact time) and high removal efficiency(high removal rate), typically for $\mathrm{Cd} 2+$ and $\mathrm{Zn} 2+$ here. 4 kinds of ions were ranked $\mathrm{Cd} 2+>\mathrm{Zn} 2+>\mathrm{Pb} 2+\sim \mathrm{Cr} 6+$ by removal rate in Fig.3.

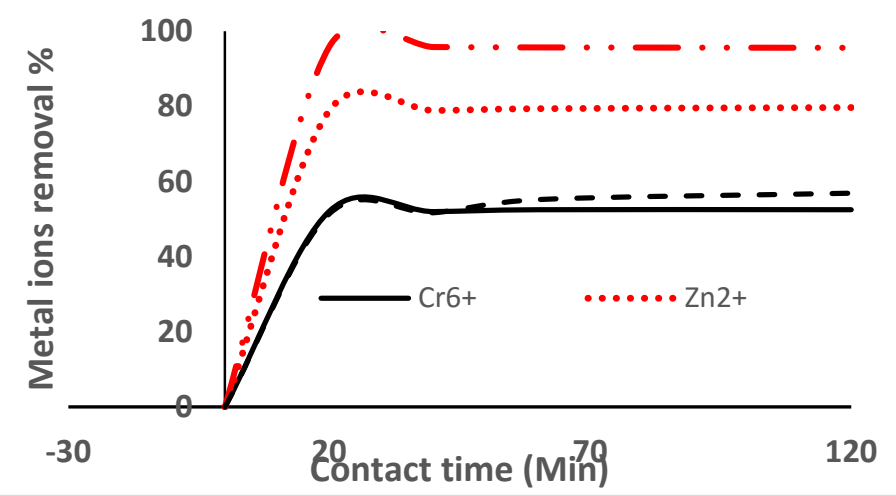

Fig 3 Effect of contact time on heavy metal ions removal by magnetic MFC aerogel. 
Figure 4 is different initial metal ions concentration effect on removal percent using $5 \mathrm{mg}$ aerogel and 60min contact time. 4 kinds of ions performed differently. Cr6+ and Zn2+ ions removal rate had little effect on initial concentrations since their curves are almost flat in Figure 4.But Zn2+ was removed around $80 \%$, much more than $\mathrm{Cr} 6+$, over $50 \%$ removal rate by the aerogel. $\mathrm{Cd} 2+$ and $\mathrm{Pd} 2+$ had better removal rate at lower initial concentration, typically below $100 \mathrm{mg} / \mathrm{L}$ here. At higher initial concentration, both ions removal rate decreased, especially $\mathrm{Cd} 2+.4$ kinds of ions removal rate ranked $\mathrm{Zn} 2+>\mathrm{Cd} 2+\sim \mathrm{Cr} 6+>\mathrm{Pb} 2+$ at higher initial separation concentration in Fig.4.

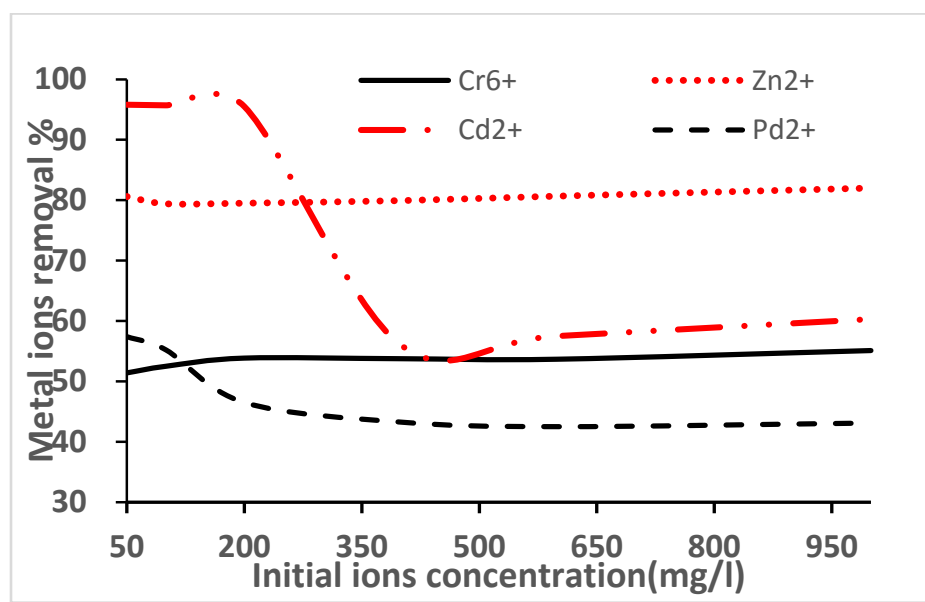

Fig. 4. Effect of initial metal ions concentration on percent removal by magnetic aerogel

The amount of metal ion adsorbed on the aerogel, qe (mg/g), was calculated according to eq 1:

$$
q_{e}=\frac{(\mathrm{C} 0-\mathrm{Ce}) \mathrm{V}}{W}
$$

where $\mathrm{C} 0$ and $\mathrm{Ce}$ are the initial and equilibrium metal ion concentrations $(\mathrm{mg} / \mathrm{L}), \mathrm{V}$ is the volume of the metal ion solution used in the adsorption experiment $(\mathrm{mL})$, and $\mathrm{W}$ is the weight of the aerogel (mg), respectively. Different initial concentration qe was calculated in Table 1.

Tab 1 Experimental qe Values (mg/g)

\begin{tabular}{|l|l|l|l|l|}
\hline $\begin{array}{l}\text { Initial Con. } \\
\mathrm{mg} / \mathrm{L}\end{array}$ & $\mathrm{Cd} 2+\mathrm{qe}$ & Zn2+ qe & Pb2+ qe & Cr6+ qe \\
\hline 50 & 479 & 403 & 287 & 257 \\
\hline 100 & 478.5 & 397 & 276 & 262.5 \\
\hline 200 & 477.5 & 397.5 & 232.5 & 269.3 \\
\hline 400 & 280 & 399.6 & 216.3 & 268.8 \\
\hline 600 & 287.5 & 403.3 & 212.5 & 268.3 \\
\hline 1000 & 301.5 & 410 & 215.5 & 275.5 \\
\hline
\end{tabular}

*Contact time 60min, $\mathrm{pH}=6$

In Tab 1, 4 kinds of ions had very higher qe values, much higher than other similar magnetic absorbent, which Cd2+ of $119.45 \mathrm{mg} / \mathrm{g}$ and $\mathrm{Pb} 2+$ of $118.56 \mathrm{mg} / \mathrm{g}$ were reported[16].

\section{Conclusions}

The magnetic MFC aerogel was applied in 4 kinds of metal ions separation successfully. The aerogel could absorb the ions fast. 4 kinds of ions removal rate were ranked $\mathrm{Cd} 2+>\mathrm{Zn} 2+>\mathrm{Pb} 2+\sim \mathrm{Cr} 6+$ at same ions initial concentration of $100 \mathrm{mg} / \mathrm{L}$. The contact time has little effect on ions removal rate. The ions initial concentration has effect on their removal rate. With 60 min contact time, 4 kinds of ions removal rate ranked $\mathrm{Zn} 2+>\mathrm{Cd} 2+\sim \mathrm{Cr} 6+>\mathrm{Pb} 2+$ at higher initial separation concentrations. The magnetic aerogel had very high absorbent capacity. 


\section{Acknowledgement}

The research was assisted by Dr. Juliana Da Silva. Prof. Orlando Rojas of North Carolina State University (Raleigh, NC 27695, USA

) gave constructive suggestions and support in order to complete the work. The author are grateful to them.

\section{References}

[1] C. Ji, S. Song, C. Wang, C. Sun, R. Qu, C. Wang, H. Chen, Preparation and adsorption properties of chelating resins containing 3-aminopyridine and hydrophilic spacer arm for $\mathrm{Hg}(\mathrm{II})$, Chem. Eng. J. 165 (2010) 573-580.

[2] J. Songa, H. Konga, J. Jang, Adsorption of heavy metal ions from aqueous solution by polyrhodanine-encapsulated magnetic nanoparticles, J. Colloid Interface Sci. 359 (2011) 505511.

[3] H.A. Aziz, M.N. Adlan, K.S. Ariffin, Heavy metals (Cd, Pb, Zn, Ni, Cu and Cr(III)) removal from water in Malaysia: Post treatment by high quality limestone, Bioresour. Technol. 99 (2008) 1578-1583.

[4] M.E. Argun, S. Dursun, A new approach to modification of natural adsorbent for heavy metal adsorption, Bioresour. Technol. 99 (2008) 2516-2527.

[5] E. Repoa, J.K. Warchołc, A. Bhatnagard, M. Sillanpää, Heavy metals adsorption by novel EDTA-modified chitosan-silica hybrid materials, J. Colloid Interface Sci. 358 (2011) 261-267.

[6] X. Zhao, L. Song, Z. Zhang, R. Wang, J. Fu, Adsorption investigation of MA-DTPA chelating resin for $\mathrm{Ni}(\mathrm{II})$ and $\mathrm{Cu}(\mathrm{II})$ using experimental and DFT methods, J. Mol. Struct. 986 (2011) 68-74.

[7] A. Srinivasan, T. Viraraghavan, Decolorization of dye wastewaters by biosorbents: A review, J. Environ. Manage. 91 (2010) 1915-1929.

[8] S. Rosa, M.C. Laranjeira, H.G. Riela, V.T. Fávere, Cross-linked quaternary chitosan as an adsorbent for the removal of the reactive dye from aqueous solutions, J. Hazard. Mater. 155 (2008) 253-260.

[9] N. Ferrah, O. Abderrahim, M.A. Didi, D. Villemin, Removal of copper ions from aqueous solutions by a new sorbent: Polyethyleneiminemethylene phosphonic acid, Desalination 269 (2011) 17-24.

[10] X. Jing, F. Liua, X. Yanga, P. Linga, L. Li, C. Longa, A. Li, Adsorption performances and mechanisms of the newly synthesized N,N'-di(carboxymethyl) dithiocarbamate chelating resin toward divalentheavy metal ions from aqueous media, J. Hazard. Mater. 167 (2009) 589-596.

[11] M.E. Mahmoud, I.M. Kenawy, M.A.H. Hafez, R.R. Lashein, Removal, preconcentration and determination of trace heavy metal ions in water samples by AAS via chemically modified silica gel N-(1-carboxy-6-hydroxy) benzylidenepropylamine ion exchanger, Desalination 250 (2010) 62-70.

[12] J. Aguado, J. Arsuaga, A. Arencibia, M. Lindo, V. Gascn, Aqueous heavy metals removal by adsorption on amine-functionalized Mesoporou silica, J. Hazard. Mater. 163 (2009) 213-221.

[13] E. Eren, Removal of copper ions by modified Unye clay, J. Hazard. Mater. 159 (2008) 
235-244.

[14] W.S. Wan Ngaha, L.C. Teonga, M.A.K. Hanafiaha, Adsorption of dyes and heavy metal ions by chitosan composites: A review, Carbohydrate Polym. 83 (2011) 1446-1456.

[15] R. Laus, T.G. Costa, B. Szpoganicz, V.T. Favere, Adsorption and desorption of Cu(II), $\mathrm{Cd}(\mathrm{II})$ and $\mathrm{Pb}(\mathrm{II})$ ions using chitosan crosslinked with epichlorohydrintriphosphate as the adsorbent, J. Hazard. Mater. 183 (2010) 233-241

[16] Ozgur Ozay, Sema Ekici, Yakup Baran, et al, Utilization of magnetic hydrogels in the separation of toxic metal ions from aqueous environments, Desalination 260 (2010) 57-64. 